May 24, 2000

\title{
Can We Really Observe Hyperbolic Discounting?*
}

\author{
Jesús Fernández-Villaverde \\ Arijit Mukherji \\ University of Minnesota \\ Federal Reserve Bank of Minneapolis
}

\begin{abstract}
This paper reviews the evidence that supports hyperbolic discounting and proposes a new, more robust, experiment to test it. Recently, a growing literature has studied intertemporal choice when individuals discount over short horizons at a higher rate than over long horizons. This feature, known as hyperbolic discounting, generates dynamic inconsistency in choices, in contrast with the usual assumption of a constant discount rate, known as exponential discounting, where this problem cannot arise. Hyperbolic discounting is justified based on evidence from experiments in psychology that suggest problems of self-control. We argue that this interpretation depends crucially on the absence of uncertainty. We show that, once uncertainty is included, existing evidence can be made compatible with exponential discounting. We test the presence of hyperbolic discounting in a new experiment that controls for uncertainty. The experiment offers two choice sets, the second being a strict subset of the first. Exponential discounters will always (possibly weakly) prefer the largest one. Hyperbolic discounters, in contrast, will (strictly) prefer the second set because its design makes it equivalent to a commitment technology. The experiment is then conducted on a sample of undergraduate students. Our results suggest that hyperbolic behavior is much more difficult to find than implied by previous experiments.
\end{abstract}

*Research Department, Federal Reserve Bank of Minneapolis, 90 Hennepin Av. Minneapolis, MN 55480. E-mail: jesusfv@atlas.socsci.umn.edu, arijit@umn.edu. Thanks to V.V. Chari, Juan Carlos Conesa, John Dickhaut, Carlos Garriga, Tom Holmes, Karsten Jeske and Narayana Kocherlakota for useful comments. Beyond the usual disclaimer, we must notice that any views expressed herein are those of the authors and not necessarily those of the Federal Reserve Bank of Minneapolis or of the Federal Reserve System. 


\section{Introduction}

Recently, a growing literature has concentrated on the study of the dynamic choices of individuals that discount over short horizons at a higher rate than over long horizons. This feature is known as hyperbolic discounting. Examples of this literature include Barro (1999), Caplin and Leahy (1999), Diamond and Köszegi (1999), Harris and Laibson (forthcoming), Gul and Pesendorfer (1999), Jovanovic and Stolyarov (2000), Krusell and Smith (1999), Laibson (1996, 1997) and O’Donoghue and Rabin (1997a, 1997b and 1999) among many others. These models explore a very particular characteristic of this kind of preferences: their inducement of dynamically inconsistent choices as defined by Strotz (1955): if individuals have the opportunity to revise their plans in the future, they will deviate from their original choices.

This inconsistency can substantially change the behavior of agents with respect to the predictions of standard neoclassical theory. In particular, it has been argued that this approach can account for issues such as addictions that are difficult to explain within the traditional framework (see Akerlof (1991) and Becker and Murphy (1988)). Moreover, these models can also have important policy implications for financial innovation or social security reform (see Imrohoroğlu et al. (1999) and Laibson et al. (1998)). Dynamically inconsistent consumers would undersave if they are not constrained by commitment devices such as mandatory social security retirement or limited participation in financial markets. As a consequence, the proposed movement towards less regulated systems might lower social welfare.

The principal piece of evidence presented to support hyperbolic discounting is a common anomaly observed in experiments as reported by Loewenstein and Thaler (1989), Loewenstein and Prelec (1992) and Ainslie (1991 and 1992): when confronted with the choice between two payments close in time (i.e. $\$ 10$ today vs. $\$ 11$ tomorrow), an important share of the population prefers the immediate payment even if that implies an incredibly high discount rate (in this case $7.79 \exp (-16)$ in an annual basis). However, most of the agents choose $\$ 11$ in 101 days over $\$ 10$ in 100 days, even if the relative distance of both payments is the same as that in the first case.

The proposed explanation for this behavior is that agents discount the future hyper- 
bolically: with a much greater discount rate in the short-run than in the long-run. Given this changing discounting, they prefer $\$ 10$ today and $\$ 11$ in one hundred days ${ }^{1}$. Either a generalized hyperbola $(1+\alpha t)^{-\frac{\gamma}{\alpha}}$ with $\alpha, \gamma>0$ or the more mathematically convenient quasi-hyperbola $\delta \beta^{t}$, with $\beta, \delta<1$, are suggested as an appropriate discount factor for events at time $t$.

This paper makes three points. First, it presents an alternative explanation for the described anomaly in choices: uncertainty. Since uncertainty for the period (in preferences, endowments or technology) is already revealed at the moment of the experiment, it only plays a role in the next period. However, when the two options are in the future, uncertainty is relevant for both of them. It is shown how even a relatively small degree of uncertainty can generate the observed behavior in a standard model of dynamic choice. The consequence is simple: if uncertainty can also generate these apparently contradictory choices, the existing evidence is not conclusive about how agents discount over time.

The second point of the paper is then to propose a procedure to test for the presence of hyperbolic discounting in an experiment that controls for uncertainty. The new experiment offers two choice sets, the second being a strict subset of the first. Exponential discounters will always (possibly weakly) prefer the largest one. Hyperbolic discounters, in contrast, will (strictly) prefer the second set because its design makes it equivalent to a commitment technology: their choice set is restricted to some particular path of action. The experiment is then conducted on a sample of undergraduate students. The results imply that hyperbolic behavior is much more difficult to find than suggested by previous experiments.

This result is also important in raising a more general, third, point: the need to control for confounding effects in experiments more carefully.

The laboratory evidence that documents the previously mentioned dynamically inconsistent choice pattern is an example of how in the last two decades experiments have become a normal way to learn from direct observation of agents' behavior (for a general review see Kagel and Roth (1995)). Particularly, experiments have been used to document systematic departures from rational choice theory (Camerer (1995)). However, the main idea behind the

\footnotetext{
${ }^{1}$ However, variable discount factors are not sufficent conditions for temporal inconsistency. See the work of Koopmans (1960) or, more recently, Becker and Mulligan (1997).
} 
use of experiments in other sciences is controllability, a goal extremely difficult to achieve in economic experiments. For instance, it is not easy to convince the subjects in the experiment of the credibility of the experimenter ${ }^{2}$ or to be sure that everyone really understands the instructions properly. These factors could induce the agent to select the most secure choices even if differences in utilities are substantial. We will briefly comment on three of those problems with experiments ${ }^{3}$.

The first factor is learning, especially the learning of the experimental instructions. Any set of explicit rules in is completed with another, more extensive, set of implicit rules that arise from the first and agents need some time to understand them properly. The best possible example is chess: even if basic rules are extremely simple, it takes a whole life (and arguably much more than that) to learn to play it properly. Indeed, there is some evidence that when experiments are repeated over the same population, convergence towards behavior implied by standard economic theory is observed (see Miller, Rust and Palmer (1994)). In the same line, Friedman (1998), building on Gigerenzer (1991), claims that each choice "anomaly" can be greatly diminished or entirely eliminated in appropriately structured learning environments. In the context of hyperbolic discounting experiments, learning is relevant both because of the existence of prior uncertainty about default rates of the experimenter ${ }^{4}$ and because the choice problems devised to detect hyperbolic discounting use of relatively sophisticated mechanisms such as second-bid auctions (as in Horowitz (1991) and Kirby (1997)) to elicit responses.

The second factor is the existence of outside opportunities that the agent accounts for. An interesting example is in Mulligan (1996): monetary experiments such as the one outlined above are not able to detect hyperbolic discounting. In an economy with financial markets, the only relevant parameter for choice is not the discount factor but the interest rate. In the presence of financial markets, agents can rearrange their cash-flows into optimal consumption streams. Then, a simple explanation for the outcome of these monetary experiments could be

\footnotetext{
${ }^{2}$ Even a low probability (around $9 \%$ for a risk-neutral agent) assigned to the belief that the experimenter will not pay in the next period will explain the choice of $\$ 10$ today over $\$ 11$ tomorrow. If the default probability decays hyperbolicaly, this choice is also compatible with selecting $\$ 11$ in the future.

${ }^{3}$ Harrison, Harstad and Rutström (1995) present related but independent comments about the ability of experimental methods to elecit values.

${ }^{4}$ And more generally uncertainty about the working of the experiment as a whole: all the experiments use one-shot choices.
} 
the experimental subjects' lack of knowledge of the arbitrage possibilities offered by financial markets. But this is precisely the case in which learning can make a difference. We can take Mulligan's example further and argue that if we prefer to assume that access to financial markets is limited, the relevant element of choice is not anymore the discount factor but the ratios of marginal utilities evaluated at the constrained levels of consumption. Again the existing experimental evidence involving money lacks a clear interpretation ${ }^{5}$.

The third factor is the presence of uncertainty. Standard economic theory predicts very different behavior with and without uncertainty. This paper shows how this uncertainty can be very important to interpret correctly any experimental evidence and how it can reverse the burden of the proof against hyperbolic discounting.

The rest of the paper is structured as follows. Section 2 presents a extremely simple model of dynamic choice with uncertainty. Section 3 describes the experiment. Section 4 reports the experimental results. Section 5 compares our results with those in the previous literature and finally section 6 concludes. An appendix includes the instructions of the experiment.

\section{A Model with Uncertainty}

Consider an economy with a continuum of agents with measure 1. Each consumes over time and discounts the future with a factor $\beta$. Given a period utility function $U(\cdot)$ : $\Re_{+} \rightarrow \Re$, the problem she solves is:

$$
\max _{\left\{c_{t}\right\}_{t=0}^{\infty}} \sum_{t=0}^{\infty} \beta^{t} E_{0} U\left(A_{t} c_{t}\right)
$$

where $c_{t}$ is the consumption in the period, $A_{t} \in(0, \infty)$ is an idiosyncratic, independentacross-time shock to preferences, revealed at the beginning of each period beofer consumption is made, with an $L_{2}$-distribution $P$ over the Borel $\sigma$-field of subsets of $\Re_{+}$, $\phi$, such that $P(\Upsilon)>0$ for all sets $\Upsilon \subseteq \phi . E_{0}$ is just the expectation operator evaluated at time 0 given $P$. It will also be assumed that the population follows an adequate law of large numbers (Uhlig

\footnotetext{
${ }^{5}$ These objections are not adequate for cases where the offers involve the direct consumption of a specific good when there are no markets to trade present and future consumption streams of the good. A frequently cited case involves undergraduates choosing between longer and shorter periods of access to a video game (Millar and Navarick (1984)).
} 
(1996)). The utility function satisfies the usual properties: $U(\cdot) \in C^{2}, U^{\prime}(\cdot)>0, U^{\prime \prime}(\cdot)<0$ for all $c_{t}$ in $\Re_{+}$. Further, $U(\cdot)$ is also bounded below at 0 .

Given these assumptions, the following lemma holds:

Lemma 1. $\int U\left(A_{t} c_{t}\right) d P$ is bounded for all $c_{t}$ in $\Re_{+}$.

Proof. As $P$ is $L_{2}$, for a given $c_{t}, \int A_{t} c_{t} d P<\infty$. As $U^{\prime \prime}(\cdot)<0$, by the Hyperplane Separation Theorem there are some constants $a$ and $b$ such that $U\left(A_{t} c_{t}\right) \leq a A_{t} c_{t}+b$. Then $\int U\left(A_{t} c_{t}\right) d P \leq a \int A_{t} c_{t} d P+b<\infty$

From Lemma 1 the maximization problem is well defined and the usual theorems in choice theory follow easily.

We will try to show how agents in this economy will behave differently when faced with apparently similar problems. In particular we will study the case when agents face the two following choice problems:

1. Consuming $c^{\prime}$ units of the good in $n$ periods or $c^{\prime \prime}$ units of the good in $n+1$ periods.

2. Consuming $c^{\prime}$ units of the good today or $c^{\prime \prime}$ units of the good tomorrow.

We will assume these consumptions units are non tradable. As a consequence there is no role for insurance among agents. The following proposition is straightforward.

Proposition 1. All the agents will prefer the same option in the choice problem 1.

Proof. For every agent, the utility of consuming at time $n$ is:

$$
\beta^{n} \int U\left(A_{n} c^{\prime}\right) d P
$$

and the utility of consuming at time $n+1$ is:

$$
\beta^{n+1} \int U\left(A_{n+1} c^{\prime \prime}\right) d P
$$

Since, by Lemma 1 both expressions are bounded constants and by the independence assumption of the shocks, they have the same value for all consumers in the economy regardless 
of $A_{0}$, all agents will opt for consumption in the same period. Note that, under indifference, we can assume a common choice in either direction.

Without loss of generality assume that the consumption units in the choice problem 1 is such that:

$$
\beta \int U\left(A_{n+1} c^{\prime \prime}\right) d P \geq \int U\left(A_{n} c^{\prime}\right) d P
$$

Then, all agents will wait until period $n+1$, as observed in experiments. Now, we can prove the next Proposition.

Proposition 2. Different agents will take different options in the choice problem 2.

Proof. For every agent, the utility of consuming at time 0 is:

$$
U\left(A^{\prime} c^{\prime}\right)
$$

where $A^{\prime}$ is the realization of the preferences shock at time 0 . The utility of consuming at time 1 is:

$$
\beta \int U\left(A_{1} c^{\prime \prime}\right) d P
$$

Since $U(\cdot)$ is invertible, given its assumed properties, there exist an $A^{*}$ such that:

$$
A^{*}=\left(U^{-1}\left(\beta \int U\left(A_{1} c^{\prime \prime}\right) d P\right)\right) / c^{\prime}
$$

so, all agents with $A^{\prime} \geq A^{*}$ will opt for consumption in period 0 and all agent with $A^{\prime} \leq A^{*}$ will wait until period 1.

By assumption both $P\left(\left[A^{*}, \infty\right)\right)>0$ and $P\left(\left(0, A^{*}\right)\right)>0$ and by the law of large numbers those measures coincide with the population measures.

Proposition 1 and 2 show that, under uncertainty, the behavior of agents will present differences between choices that involved only the future and choices than involve both the present and the future.

The intuition for this result is straightforward. In choice problem 2, the agent knows for sure how much utility she will get from consumption today and when the present shock is 
high enough, she would prefer present utility. Indeed, this shock does need to be very high in absolute terms because she is risk-averse. When both choices are in the future, uncertainty plays a symmetric role and the only relevant factor is then the discount factor.

To further illustrate this point we present a numerical example. We will consider a modified CRRA utility function:

$$
U=\frac{\left(A_{t} c_{t}+\varepsilon\right)^{1-\sigma}-1}{1-\sigma}
$$

where $\varepsilon$ is a real number to bound below the utility function and small enough to be numerically irrelevant. We will use days as the unit in which time is measured.

Let us assume that $A_{t}$ is distributed as:

$$
\log A_{t} \sim \mathcal{N}\left(1, \theta_{A}\right)
$$

Finally, $\beta$ can be fixed at 0.9999 (equivalent to a 0.96 annual discount factor) and, to retain figures from the standard example, the consumption levels at 10 for $c^{\prime}$ and 11 for $c^{\prime \prime}$.

Then, for $\sigma=2$ and $\theta_{A}=0.25$, a 0.52 share of agents would prefer to consume today vs. tomorrow and all of them will prefer consumption in $n+1$ over consumption in $n$. Even if the variance of the preference shock is reduced, a sizeable part of the population will keep this choice as shown in figure [1]. For instance, with a variance of 0.04 , still a fraction of 0.36 of the population will opt for present consumption. We can move towards higher risk-aversion, i.e. closer to its econometric estimations (see Campbell, Lo and MacKinlay (1997)). For $\sigma=3$ and $\theta_{A}=0.25$ the fraction choosing present consumption is as high as 0.64 . Even with a variance as low as 0.01, a third of the population will prefer present consumption ${ }^{6}$.

Is this a fair example? Are these variances plausible? It is hard to judge. However, it seems reasonable to defend the hypothesis that preferences suffer shocks over time. According to Laibson (forthcoming) "preferences change rapidly from time to time". A simple explanation takes the utility function as a production function that produces services for the self and suffers from technology shocks. For example, the ability to appreciate a movie can

\footnotetext{
${ }^{6}$ For comparison purposes note Ainslie and Haendel (1982) found that only $33 \%$ of subjects made inconsistent choices when faced with real payoffs.
} 
depend crucially on elements such as the theater temperature or the number of people in the room. Another justification is to see the utility function as some reduced form of a much more complicated problem where the capacity to enjoy a good depends on the consumption of many other goods that the economist does not want to model explicitly ${ }^{7}$.

Nevertheless, the point is simple: relatively small changes in the utility function can explain experimental findings at least as well as hyperbolic discounting without any of its rather troubling consequences.

\section{An Alternative Experiment}

The existence of an alternative to hyperbolic discounting as an explanation for the reported behavior pattern raises the need to collect more empirical evidence to distinguish between the two models of discounting.

A first, natural approach to test the two hypotheses about discounting would be to use micro data on consumption. Harris and Laibson (1999) have derived the Euler relations for the Hyperbolic Discounter problem. This development would suggest the use of these Euler equations to test the empirical performance of hyperbolic discounting ${ }^{8}$. We believe, however, that using this approach is problematic. The implied consumption policy functions will tend to have very similar behavior under subgame perfection-hyperbolic discounting and under the exponential discounting (see Laibson et al. (1998)). Under these circumstances, the relatively poor small sample performance of moment estimators (Burnside and Eichenbaum (1996)) and the usual measurement errors of micro data will make it extremely difficult to distinguish the two alternative explanations in the data.

This kind of problems with micro data induce us to focus on the original source of empirical evidence regarding hyperbolic discounting: experiments on individual intertemporal choice. However, given our previous discussion about existing experiments, we want to design a new, more robust experiment to detect hyperbolic discounting. Three general points must be considered in this design:

\footnotetext{
${ }^{7} \mathrm{~A}$ similar approach would consist of endowing agents with random amounts of the consumption good so the uncertainty would be related with the level of marginal utility in the next period. Both models have equivalent implications for some appropriate parametrization.

${ }^{8}$ This test will be in the spirit of Hausman (1979). He estimated the implied discount factors by the observed choice between future energy costs and current prices of durables.
} 
1. Implicit cost. All the implicit costs for every alternative must be equalized so they do not distort the choice in favor of any alternative.

2. Uncertainty. The design must assure that random shocks to preferences influence the choices symmetrically.

3. Absence of outside markets for the good offered.

With these considerations in mind we will propose the following experiment involving minutes of access of undergraduates to videogames ${ }^{9}$.

The agents in the new experiment are presented with the next two alternatives:

- Option A: Get a bond for 180 minutes of access to videogames that can be played in the laboratory in three consecutive days after some specified date in the future. So if the specified date is $n$ they can use the minutes in $n+1, n+2$ and $n+3$. The distribution of time is constrained by the experiment to be 60 minutes on the first day, 60 minutes on the second and 60 minutes on the last day. They must go to the laboratory for the experiment on all the three days and sign an attendance sheet.

- Option B: Get a similar bond for 180 minutes of access to videogames that can be played in the laboratory in three consecutive days after some specified date in the future. So if the specified date is $n$ they can use the minutes in $n+1, n+2$ and $n+3$. They are free to distribute that time as they wish over the three days but they should go to the laboratory for the experiment on all the three days and sign an attendance sheet.

An exponential discounting agent would always opt for the second alternative, regardless of the degree of uncertainty associated with preferences shocks. Since she is able to design dynamically consistent plans, she solves the value function problem for $t \in\{n+1, n+2\}$ :

$$
\begin{aligned}
V\left(A_{t}, M_{t}, t\right) & =u\left(A_{t} c_{t}\right)+\beta \int V\left(A_{t+1}, M_{t+1}, t+1\right) d P \\
V\left(A_{3}, M_{3}, 3\right) & =u\left(A_{3} c_{3}\right)
\end{aligned}
$$

\footnotetext{
${ }^{9}$ The use of videogames has been suggested by Millar and Navarick (1984).
} 


$$
\begin{aligned}
\text { s.t. } M_{t+1} & =M_{t}-c_{t} \\
M_{n} & =180
\end{aligned}
$$

where the states are the period shock $A_{t}$, the time $t$ and $M_{t}$ are the remaining minutes to be consumed. The solution of this problem $\int \beta^{n+1} V^{*}\left(A_{t}, 100,1\right) d P$ is at least as high as $\sum_{t=n+1}^{3} \beta^{t} E_{0} U\left(A_{t} 60\right)$ as she can always replicate, by herself, the second alternative (the solution of an unconstrained problem is at least as high as the constrained one). In addition, in a generic case, she can rearrange the consumption stream to account for the discount factor and the uncertainty, and then:

$$
\int \beta^{n+1} V^{*}\left(A_{t}, 100,1\right) d P>\sum_{t=n+1}^{3} \beta^{t} E_{0} U(60)
$$

This result is well known and it can be traced back to Koopmans (1964) and Kreps (1979): in the presence of uncertainty, it is rational to show a "preference for flexibility".

What would a hyperbolic discounting agent prefer? To analyze her choice, a bit more of structure is needed. Assume, as in Phelps and Pollack (1968), that the total utility of consuming at times $n+1, n+2$ and $n+3$, evaluated at 0 is represented by:

$$
V_{0}=E_{0}\left[U\left(c_{0}\right)+\delta \sum_{t=n+1}^{n+3} \beta^{t} E_{0} U\left(c_{t}\right)\right]
$$

and that the period utility function, as in the example in the last section, is:

$$
U=\frac{\left(A_{t} c_{t}+\varepsilon\right)^{1-\sigma}-1}{1-\sigma}
$$

The utility under option B is just:

$$
V_{0}^{2}=\delta \sum_{t=n+1}^{n+3} \beta^{t} \int \frac{\left(A_{t} 60+\varepsilon\right)^{1-\sigma}-1}{1-\sigma} d P
$$

For the first option, the game of the agent against herself must be solved as described in Laibson (1996) and to find the associated Nash Equilibrium ${ }^{10}$. The solution of this problem

\footnotetext{
${ }^{10}$ More recently Caplin and Leahy (1999) have proposed a recursive formulation of the problem. However
} 
under uncertainty is given by backward induction, given the response function of the self in period $n+2$ (the last one where decisions are made) and the associated utility as evaluated at $n+1$, the self in $n+1$ will decide how much to consume. Let $W$ be the total minutes available at the beginning of period $n+1$. Then:

$$
\begin{aligned}
c_{n+1} & =\frac{k^{\prime}}{1+k^{\prime}} W \\
c_{n+2} & =\frac{k}{\left(1+k^{\prime}\right)(1+k)} W \\
c_{n+3} & =\frac{1}{\left(1+k^{\prime}\right)(1+k)} W
\end{aligned}
$$

where $k$ and $k^{\prime}$ are functions of $A_{n}, A_{n+1}$ and $A_{n+2}$.

The utility is then, as evaluated by the self at present time:

$$
\begin{aligned}
V_{0}^{1}= & \delta \beta^{n} \int_{A_{1}} \frac{\left(\frac{A_{1} k^{\prime}}{1+k^{\prime}} W\right)^{1-\sigma}-1}{1-\sigma} d P+\delta \beta^{n+1} \int_{A_{1}, A_{2}} \frac{\left(\frac{k}{1+k^{\prime}} \frac{A_{2}}{1+k} W\right)^{1-\sigma}-1}{1-\sigma} d P+ \\
& +\delta \beta^{n+1} \int_{A_{1}, A_{2}, A_{3}} \frac{\left(\frac{1}{\left(1+k^{\prime}\right)(1+k)} W\right)^{1-\sigma}-1}{1-\sigma} d P
\end{aligned}
$$

As this integral does not have an analytic solution, numerical methods are needed to evaluate it. This evaluation shows how there are present two different forces with opposite effects. On one hand, the self-control problem reduces utility with respect to the exponential discounting problem. On the other hand, the lack of flexibility in option A increases the utility of option B even for hyperbolic discounters. We evaluated this integral for $\sigma=2$, $\beta=0.999, \delta=0.6$ and $\log A_{t} \sim \mathcal{N}\left(1, \theta_{A}\right)$. We found than, in general, we will have $V_{0}^{2}>V_{0}^{1}$. Exceptions occur when the variance of the preference shock and the risk aversion are very high, cases where, as shown in section 2, standard theory explains without any problem the observed preference for present consumption.

This experiment embodies the idea of Gul and Pesendorfer (1999): a hyperbolic discounter may prefer a reduced set of alternatives to a bigger one. This smaller set is just a commitment technology and its availability increases the welfare of agents. This point also

in our case the game theoretic approach is simpler. 
parallels the analysis in Laibson (1994): agents with self-control problems like to have access to a "binding automaton", a commitment device that restricts the freedom of choice of future selves.

From the discussion above we can conclude that the design of this experiment presents some interesting properties:

1. Generates different, behavioral, predictions for exponential and for hyperbolic discounters with little external structure in the decision framework.

2. Controls for hidden cost: both alternatives requires that all subjects travel all three days to the laboratory. This cost, if any, is then independent of the amount of minutes played each day.

3. Controls for uncertainty: moving all relevant payoffs into the future removes any possible asymmetry between the alternatives.

4. Eliminates outside markets for the consumption good being offered. Even if subjects can play video games elsewhere, there is no mechanism to exchange the minutes in the experiment with these outside alternatives.

5. It allows for a nice dual interpretation. If the subjects do not like the consumption good, they will see the 180 minutes as time of work. An hyperbolic discounter would tend to procrastinate (instead of overindulge) and to avoid having too many minutes at the last moment of the experiment, she would also prefer option A as a way of locking herself into working smoothly.

The intuition behind the design of the experiment is simple: hyperbolic discounters will trade off the higher flexibility of the first option (that allows them to compensate for shocks to preferences) for the commitment of the second one as they are aware of their lack of commitment. However the exponential discounters, who do not suffer from this problem, will always keep the flexibility option available. 


\section{Empirical Results}

We conducted the proposed experiment with undergraduate students at the University of Minnesota. We recruited students volunteers from three sections in intermediate microeconomics and one section in accounting. Students arrived at the laboratory on Monday, April 10th, 2000 and received instructions that are reproduced in the appendix. These instructions concluded with five questions that were intended to insure that subjects understood the details of the experiment. After subjects had read the instructions and received clarifications to any questions, they completed their choice between option A (60 minutes each day to play videogames on computers in the laboratory, two weeks later, on 24th, 25th and 26th of April) and option B (a total of 180 minutes to play videogames on computers in the laboratory, two weeks later, on 24th, 25th and 26th of April, to be allocated as they wish on those three days). After subjects completed their choices they were paid $\$ 5$. We reminded subjects that, even if they prefer to not use any of their allocated time on an specific day under option B, they were required to visit the laboratory and sign-in on each of the days, and if they completed all stages of the experiment they will be paid an additional $\$ 30$ on the 26th of April ${ }^{11}$, regardless whether they have chosen option A or B.

Two weeks later subjects came to the laboratory and were given access to the computers with the videogames installed ${ }^{12}$, according to the choices they have made on the 10th of April. We monitored subjects' use of time to insure that they did not exceed the time limits corresponding to the selected options. Subjects that signed-in all three days were paid $\$ 30$ in cash on the 26th of April.

A total of 23 subjects read the instructions and completed the choice form between option A and option B. 20 of the 23 subjects (87\%) selected option B and the remaining $3(13 \%)$ selected option A. We consider those choices as strong evidence that commitment devices are not preferred and that subjects did not seem to be worried about self-control problems ${ }^{13}$. Using the Irrelevance of Stopping Rules Principle, we decided to stop the exper-

\footnotetext{
${ }^{11}$ This amount was chosen to correspond to a rate $\$ 10$ an hour, which is at least $\$ 1$ above the prevaling hourly wage for most on-campus jobs.

${ }^{12}$ Four different videogames were installed in each computer of the laboratory. We selected the games from Amazon top-sellers list a week before the experiment trying to offer as diverse a choice of styles as possible.

${ }^{13}$ We should note that, in an exit interview at the end of the experiment, one of the subject that chose option A mentioned explicitly that she prefered option A because it was a commitment device for herself.
} 
iment at that point and not proceed with additional batches of students. On a more formal basis we conduct a Bayesian inference exercise.

Given the existence of two different alternatives, the appropriate likelihood function is a binomial distribution with unknown parameter $p$ :

$$
\mathcal{L}(x \mid p)=\left(\begin{array}{l}
n \\
x
\end{array}\right) p^{x}(1-p)^{n-x}
$$

This parameter has the interpretation as the share of the population that has exponential discounting. To complete our stochastic model we only need a prior. We believe that a flat, uniform prior on the percentage of subjects with hyperbolic discounting is a quite natural assumption. In addition, uniforms are conjugate priors for the binomial model and the posterior is distributed as a Beta with parameters $x+1, n-x+1$ :

$$
P(y)=\frac{\Gamma(n+2)}{\Gamma(x+1) \Gamma(n-x+1)} y^{x+1}(1-y)^{n-x+1}
$$

Given the results of the experiment, our posterior distribution is then a Beta with mean 0.84 and standard deviation 0.07 , moments considerably far away from supporting the widespread existence of hyperbolic discounting. A graphical view of our empirical results is included as Figure [2], that plots our prior, our posterior and the likelihood function (up to a constant factor).

Finally, we want to point out that we see our choice of prior as being very conservative. The uniform prior gives a lot of mass to regions around 0 that seem well below what any experiment has found as the percentage of the population choosing hyperbolically ${ }^{14}$.

\section{Comparison with Previous Results}

Our empirical results suggest that the evidence in favor of hyperbolic discounting is weaker than previously claimed in the literature. Several differences in the design of our experiment may account for the alternative outcomes.

We see the existence of real rewards as the main reason for these differences. Most

\footnotetext{
${ }^{14}$ For completeness note that the Maximum Likelihood estimate of $p$ is, of course, 0.87 with asymptotic standard error of 0.03. Consequently, the interpretation of these results from a classical perspective is nearly identical.
} 
experiments presented in the literature only involved hypothetical choices (as in Thaler (1981) or Benzion et al. (1989)). This hypothetical nature raises the issue of replicability under real payoffs: individuals do not have any incentive to give a reasonable answer or even to spend mental resources to think about their true preference.

We are only aware of a handful of experiments with real money payoffs. Although is beyond the scope of this paper to proceed to a formal Meta-analysis of this literature, we believe that, interestingly enough, those experiments offer by themselves a much weaker evidence in favor of hyperbolic discounting.

Ainslie and Haendel (1982) found that around a third of subjects prefer a present monetary payoff when confronted with a $25 \%$ interest rate over three days ${ }^{15}$. Holcomb and Nelson (1992) found weak evidence in favor of hyperbolic discounting when they asked undergraduate students if they preferred immediate or delayed payoffs. In the classical example of the choice between a money quantity today or a different quantity tomorrow (with a $1.5 \%$ and $3.0 \%$ a day interest rates), between $80 \%$ and $47 \%$ of subjects choose the immediate payoff, well within what can be accounted with our model of uncertainty if we do not allow for financial markets. Horowitz (1992) tested for temporal consistency in the choice of risky assets. He found important differences in choice over time but neither were they systematic nor did they imply a change at the aggregate level. However, his definition of consistency (plans are equal to actual actions) cannot identify hyperbolic discounting when the solution concept was a subgame perfection. Also the small monetary value of the payment (the expected value was between $\$ 1$ and $\$ 2$ ), the fact the subjects were not reminded of their own original choices and the presence of uncontrolled changes in financial position of subjects introduce, in our opinion, too much noise in the experiment to draw strong conclusions.

Horowitz (1991) tried to elicit directly the discount rate through a second-price auction of a bond. However the very odd behavior of subjects (they paid more for a two month bond than for a one month bond) points out important experiment design problems. Kirby (1997) also used the idea of auctioning bonds of future payments and found more robust evidence

\footnotetext{
${ }^{15}$ They comment that this choice was despite the fact that the subjects have very little money available. We interpret that fact as a problem of the test, not as a reinforcing mechanism: the standard intertemporal choice model has very different predictions when constraints are binding.
} 
in favor of hyperbolic discounting. However he did not provide any procedure to distinguish between possible anomalies in the auction by itself and in the intertemporal choice problem. In fact, for the numbers of bidders he uses (3 or 4), Kagel, Levin and Harstad (1995) have found that bidders earn positive average profits, making difficult to elicit the true values for the agents of the bond and weaking his evidence in favor of hyperbolic discounting.

In any case we should remember that all these experiments use direct money reward schemes. As discussed in the introduction this procedure does not seem the most appropriate to approach the intertemporal choice problem because of the existence of financial markets. People bidding for bonds well below their market price can as easily be interpreted as subjects that discount hyperbolically, as subjects that lack knowledge of how markets work or even as subjects with a prior over the default of the experimenter that are distributed hyperbolically.

Finally, we want to mention a limitation of our experiment that can also explain some of the differences with other results. With its present design, the experiment is unable to separate exponential discounters from naive hyperbolic discounters. These last ones, in the language of O'Donoghue and Rabin (1999), have hyperbolic preferences but do not foresee their own self-control problems. However, we see this assumption as beyond the scope of this paper. Once we allow agents to make systematic errors about the future we do not know how to understand experimental evidence: maybe subjects discount hyperbolically or maybe they just do not understand the environment in which they are acting. Trying to identify empirically these problems of continuous mistakes seems an open issue for future research.

\section{Conclusion}

Can we observe hyperbolic discounting? At this point, we believe the evidence suggests not really. It seems a robust fact that people tend to choose present goods more frequently that suggested by a simple full-information intertemporal model with exponential discounting. It has been shown that as soon as we depart from this simple model, standard neoclassical theory can account for observed behavior patterns at least as well as the hyperbolic discount and that an alternative experiment that controls for uncertainty suggests very different results.

Another alternative judges the competing theories about discounting by their empirical 
implications (as in Hausman (1979)). Here the burden of proof is definitively on hyperbolic discount side. Even if it is true that the existence of some commitment devices, such as insurance policies, can be interpreted as a prima facie proof in favor of hyperbolic discounting. The true puzzle would be why there are no more of these self-commitment devices supplied by market forces or why nothing such as the asset pricing implications of hyperbolic discounting such as the existence of Dutch Books are observed.

Our conclusion is simple. Up to this moment we have not seen enough convincing evidence, direct or circumstantial, that hyperbolic discounting is a basic characteristic of preferences.

\section{Appendix: Instructions for Individual Choice Experiment}

\section{General}

You are about to participate in an experiment in the economics of individual choice. Various research foundations have provided the funding for this project. If you follow these instructions carefully, you will earn $\$ 30$ just for playing games on the computer.

Please do not talk during the experiment. If you have any questions, raise your hand and an experimenter will assist you.

The experiment consists of your choosing between two options, A and B, and meeting

all of the requirements of the option that you have chosen. These requirements are described in section 2 below.

Once you have completed all of the requirements of the option that you have chosen, you will be paid an additional $\$ 30$ in cash. If you fail to complete all of the requirements of the option that you have chosen, you will not be paid any amount. Note that this payment does NOT depend on whether you chose B or A, but depends only on completing the requirements of the option that you have chosen. Also, the payment does NOT depend on what other subjects in this experiment choose. Just choose the option that you like the most.

\section{The Options}

You will have 180 minutes to play different games on the computers installed in the lab in 3-114 in the Carlson School of Management building from Monday to Wednesday in the week of 24th April to 26th April. Your choice concerns how you want to distribute these 
minutes.

\section{Option A}

If you choose option A), you will have 60 minutes on Monday 24th April, 60 minutes on Tuesday 25th April and 60 minutes on Wednesday 26th April. You can come in any time from 10 a.m. to 5 p.m. (from 24th April to 26th April) and then use your 60 minutes for the appropriate day in the lab.

You do have to attend on all three days. You should also sign your name on a control sheet, so we can verify that you have attended on all three days.

At the end of your last 60 minutes on Wednesday, if you have attended all three days as required, you will be paid $\$ 30$ in cash.

\section{Option B}

If you choose option B), you can decide how you want to distribute a total of 180 minutes over the three days, Monday 24th April, Tuesday 25th April and Wednesday 26th April. You can come in any time from 10 a.m. to 5 p.m. (again, from 24th April to 26th April) to the lab.

You do have to attend on all three days. You should also sign your name on a control sheet, so we can verify that you have attended on all three days. So for example, you could choose to play 100 minutes on Monday, 0 on Tuesday and 80 on Wednesday, but on Tuesday you need to come to the lab, sign the sheet and then leave if you want to play for 0 minutes on that day.

At the end of your session on Wednesday, if you have attended all three days as required, you will be paid $\$ 30$ in cash.

\section{Your choice}

After you have read the instructions, you will make your choice - between Option A and Option B - TODAY. Once you have made your choice TODAY, you CANNOT change your choice.

\section{The Games}

The lab in which you will participate in the experiment has a network with many computers. Each computer has three or more games installed on it. During your playing time, regardless of whether you have chosen Option A or Option B, you are free to change 
from one game to the other, if you wish.

\section{The Experimental Lab}

The lab is located on the 3rd floor of the Carlson School of Management Building in room 3-114. The lab will be open for this experiment 10 a.m. to 5 p.m. during the period 24th to 26th April. During this time, you may choose to attend at any time according to your schedule. If you have any questions about the experiment at any time, you may contact either Professor Mukherji by telephone (624-9825) or e-mail (amukherji@csom.umn.edu) or Jesús Fernández-Villaverde by telephone (204-5492) or e-mail (jesusfv@econ.umn.edu).

\section{Before we begin}

If you have any question regarding the experiment, ask them NOW. To ensure that you understand the instructions, please answer the following questions. An experimenter will check your answers when you are finished.

a) My payment will NOT depend on the choice of option A) or B) but in following the requirements of the option that I have chosen.

True False

b) For both options A and B, I need to come to the lab three times.

True False

c) I am allowed to change options when I want.

True False

d) Every time I go to the lab, I need to sign my name on a control sheet.

True False

e) I can play any of the games in the computer without any limitations except time. True False

\section{References}

[1] Ainslie, G. (1991), "Derivation of "Rational" Economic Behavior from Hyperbolic Discount Curves". American Economic Review 81(2), pp. 334-340.

[2] Ainslie, G. (1992), Picoeconomics, the Strategic interaction of Successive Motivational States within the Person. Cambridge University Press. 
[3] Ainslie, G. and V. Haendel (1982), "The Motives of Will" in E. Gottheil, K. Druley, T. Skolda and H. Waxman (eds) Etiologic Aspects of Alcohol and Drug Abuses, Charles C. Thomas.

[4] Akerlof, G.A. (1991), "Procranstination and Obedience". American Economic Review Papers and Proceedings 81, pp. 1-19.

[5] Barro, R. (1999), "Ramsey Meets Laibson in the Neoclassical Growth Model". Quarterly Journal of Economics CXIV, pp. 1153-1191.

[6] Becker, G.S. and C.B. Mulligan (1988), "A Theory of Rational Addiction". Journal of Political Economy 96, pp. 675-700.

[7] Becker, G.S. and C.B. Mulligan (1997), "On the Endogenous Determination of Time Prefence". Quaterly Journal of Economics CXII, pp. 729-758.

[8] Benzion, U., A. Rapoport and J. Yagil (1989), "Discount Rates Inferred from Decisions: an Experimental Study". Management Science 35, pp. 270-284.

[9] Burnside, C. and M.S. Eichenbaum (1996) "Small-Sample Properties of GMM-Based Wald Tests" Journal of Business and Economic Statistics 14(3), pp. 294-308.

[10] Camerer, C. (1995), "Individual Decision Making" in Kagel, J.H. and A. E. Roth eds, The Handbook of Experimental Economics. Princeton University Press.

[11] Campbell, J.Y., A.W. Lo and A.C. MacKinlay (1997), The Econometrics of the Financial Markets. Princeton University Press.

[12] Caplin, A. and J. Leahy (1999), "The recursive Approach to Time Consistency". Mimeo, New York University.

[13] Diamond, P. and B. Kőszegi (1999), "Quasi-Hyperbolic Discounting and Retirement". Mimeo, MIT.

[14] Friedman, D. (1998), "Monty Hall's Three Doors: Construction and Deconstruction of a Choice Anomaly". American Economic Review v. 88, pp. 933-946. 
[15] Gigerenzer, G. (1991), "How to Make Cognitive Illusions Dissapear: Beyond 'Heuristics and Biasis"'. European Review of Social Psychology, v. 2(1), pp 83-115.

[16] Gul, F and W. Pesendorfer (1999), "Dynamic Inconsistency and Self-Control". Mimeo, Princeton University.

[17] Harris, C. and D. Laibson (forthcoming), "Dynamic Choices of Hyperbolic Consumers". Mimeo, Harvard University.

[18] Harrison, G.W., R.M. Harstad and E.E. Rutström (1995), "Experimental Methods and Elicitation of Values". Mimeo, University of South Carolina.

[19] Hausmann, J. (1979), "Individual Discount Rates and the Purchase and Utilization of Energy-Using Durables" Bell Journal of Economics v 10(1), pp. 33-54.

[20] Holcomb, J.H. and P.S. Nelson (1992), "Another Experimental Look at Individual Time Preference". Rationality and Society 4, pp. 199-220.

[21] Horowitz, J.K. (1991), "Discounting Money Payoffs: An Experimental Analysis". Handbook of Behavorial Economics, v. 2B, pp. 309-324.

[22] Horowitz, J.K. (1992), "A Test of Intertemporal Consistency". Journal of Economic Behavior and Organization 17, pp. 171-182.

[23] Imrohoroğlu, A., S. Imrohoroğlu and D. H. Joines (1999), "Myopia and Social Security". Mimeo, University of Southern California.

[24] Jovanovic, B. and D. Stolyarov (2000), "Ignorance is Bliss". Mimeo, New York University.

[25] Kagel, J.H., Levin, D., Harstad, R.M. (1995), "Comparative Static Effects of Number of Bidders and Public Information on Behavior in Second-Price Common Value Auctions" International Journal of Game Theory 24(3) pp. 293-319.

[26] Kagel, J.H. and A. E. Roth (1995), The Handbook of Experimental Economics. Princeton University Press. 
[27] Kirby, K.N. (1997), "Bidding on the Future: Evidence Against Normative Discounting of Delayed Rewards". Journal of Experimental Psycology: General 26, pp. 54-70.

[28] Koopmans, T. C. (1960), "Stationary Ordinal Utility and Impatience". Econometrica 28, pp. 287-309.

[29] Koopmans, T. C. (1964), "On the Flexibility of Future Preferences" in M.W. Shelly and G.L. Bryan eds., Human Judgments and Optimality, John Wiley and Sons.

[30] Krusell, P. and A. A. Smith (1990), "Consumption-Savings Decisions with QuasiGeometric Discounting". Mimeo, Carnegie-Mellon University.

[31] Laibson, D.I. (1994), "Mental Accounts, Self-Control and an Intrapersonal PrincipalAgent Problem". Mimeo, MIT.

[32] Laibson, D.I. (1996), "Hyperbolic Discount Functions, Undersaving, and Savings Policy". NBER Working Paper 5635.

[33] Laibson, D.I. (1997), "Golden Eggs and Hyperbolic Discounting". Quaterly Journal of Economics CXII, pp. 443-447.

[34] Laibson, D. I. (forthcoming), "A Cue-Theory of Consumption". Quaterly Journal of Economics.

[35] Laibson, D.I., A. Reppeto and J. Tobacman (1998), "Self-Control and Saving for Retirement". Brookings Papers in Economic Activity v.1, pp. 91-196.

[36] Loewenstein, G. and R.H. Thaler (1989), "Anomalies: Intertemporal Choice". Journal of Economic Perspectives v.3-4, pp.181-193.

[37] Loewenstein, G. and D. Prelec (1992), “Anomalies in Intertemporal Choice: Evidence and a Interpretation" Quaterly Journal of Economics CVII, pp. 573-598.

[38] Millar, A. and D.J. Navarick (1984), "Self-Control and Choice in Humans: Effects of Video Game Playing as a Positive Reinforcer". Learning and Motivation, 15, pp. 203218. 
[39] Miller, J.H., J. Palmer and J. Rust (1994), "Characterizing Effective Trading Strategies: Insights from a Computerized Double Auction Tournament". Journal of Economics Dynamics and Control 18(1), pp. 61-96.

[40] Mulligan, C.S. (1996), "A Logical Economist's Argument Against Hyperbolic Discounting". Mimeo, University of Chicago.

[41] O'Donoghue, T. and M. Rabin (1997a), "The Economics of Immediate Gratification". Mimeo, University of California at Berkeley.

[42] O'Donoghue, T. and M. Rabin (1997b), "Addiction and Self-Control". Mimeo, University of California at Berkeley.

[43] O'Donoghue, T. and M. Rabin (1999), "Doing it Now or Doing it Later". American Economic Review 98, pp. 103-124.

[44] Phelps, E.S. and R.A. Pollack (1968), "Myopia and Inconsistency in Dynamic Utility Maximization". Review of Economic Studies, XXXV, pp. 201-208.

[45] Strotz, R. (1955), "Myopia and Inconsistency in Dynamic Utility Maximization". Review of Economic Studies, XXIII, pp. 165-80.

[46] Thaler, R. (1981), "Some Empirical Evidence on Dynamic Inconsistency". Economic Letters 8, pp. 201-207.

[47] Uhling, H. (1996), "A Law of Large Numbers for Large Economies". Economic Theory 8, pp. $41-50$. 
Figure 1: Share of Population Choosing Consumption Today

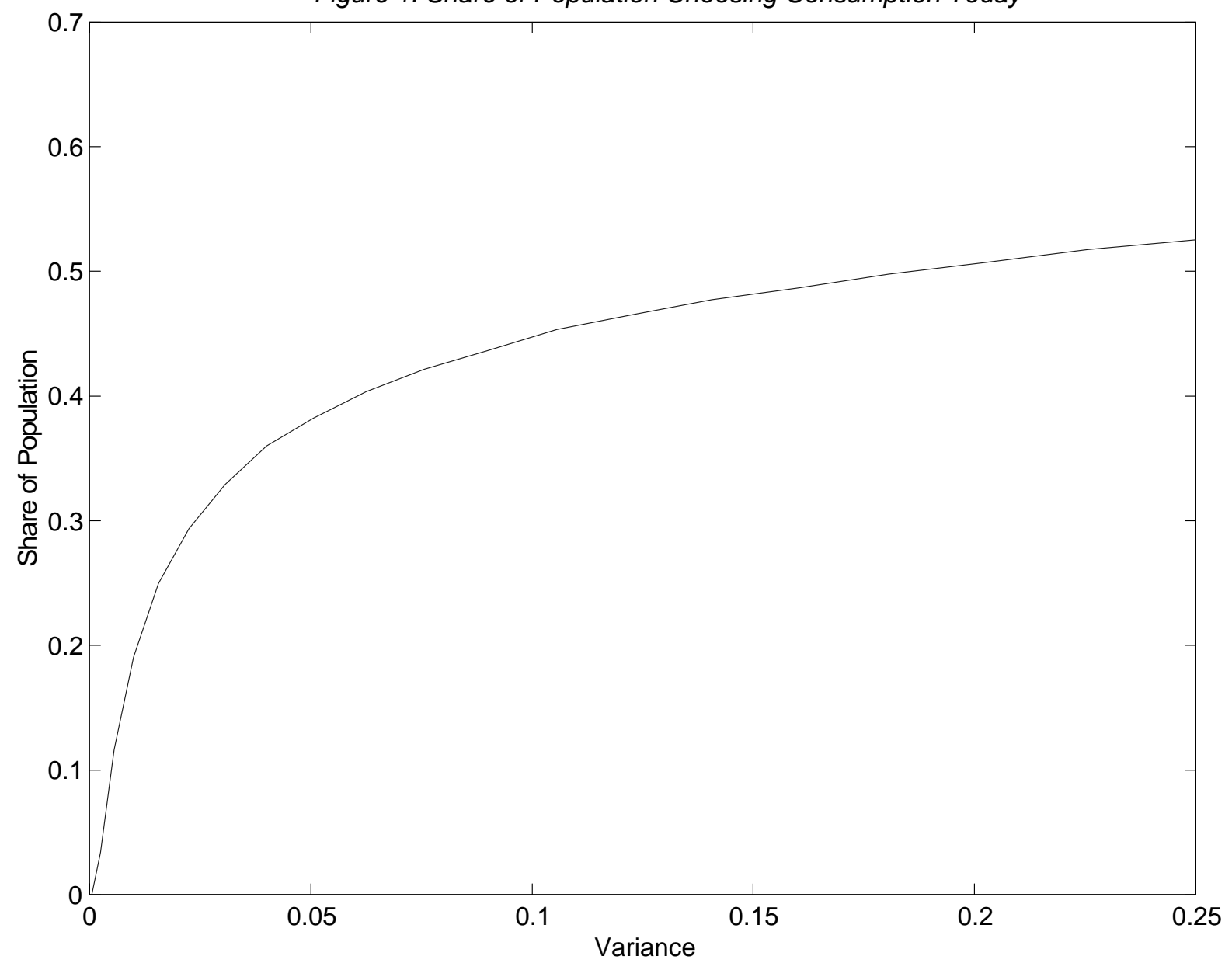


Figure 2: Prior, Posterior and Likelihood

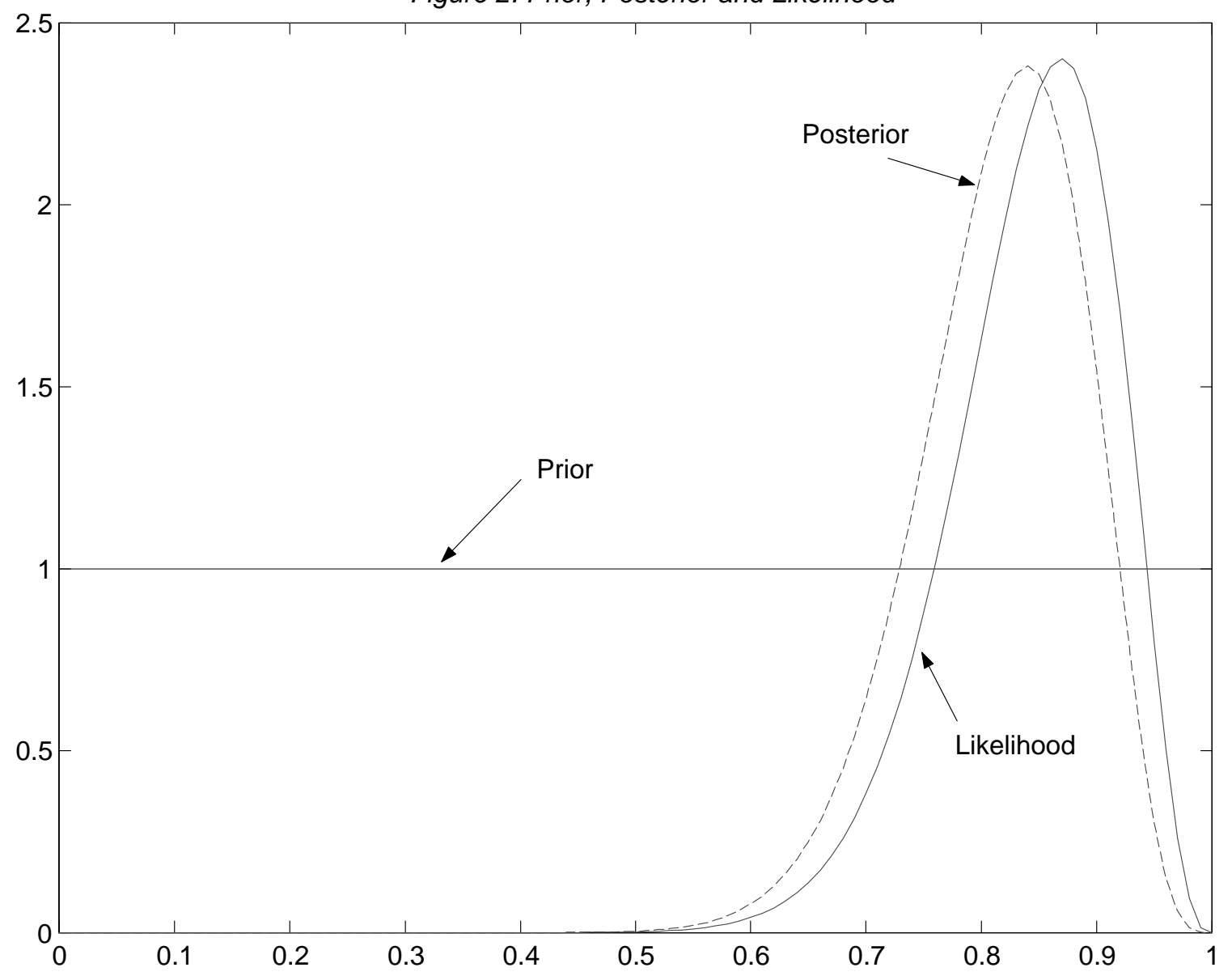

